are important predictor variables in verbal learning with meaningful stimuli as well.

\section{REFERENCES}

ANISFELD, M., \& KNAPP, M. Association synonymity, and directionality in false recognition. Journal of Experimental Psychology, 1968,77, 171-179.

ATTNEAVE, F. Transfer of experience with a class-schema to identification-learning of patterns and shapes. Journal of Experimental Psychology, 1957, 54, 81-88.

DEESE, J. Influence of inter-item associative strength upon immediate free recall. Psychological Reports, 1959, 5, 305-312.

EVANS, S. H. A brief statement of schema theory. Psychonomic Science, 1967, 8, 87-88.

HOLLIER, J., \& EVANS, S. H. Schematic concept formation with linguaform patterns. Psychonomic Science, 1967, 9, 89-90.

HOROWITZ, L. M. Free recall and ordering of trigrams. Joumal of Experimental Psychology, 1961, 62, 51-57.

KOEPPEL, J. C. Intralist similarity, internal structure, and free recall. Journal of Verbal
Learning \& Verbal Behavior, 1968, 7, 882-886. MILLER, G. A. Free recall of redundant strings of letters. Joumal of Experimental Psychology, $1958,56,485-491$.

OLDFIELD, R. C. Memory mechanisms and the theory of schemata. British Joumal of Psychology, 1954, 45, 14-23.

TULVING, E. Theoretical issues in free recall. In T. R. Dixon and D. L. Horton (Eds.), Verbal behavior and general behavior theory. Englewood Cliffs, N.J.: Prentice-Hall, 1968. Pp. 2-36. UNDERWOOD, B. J. The representativeness of rote learning. In A. W. Melton (Ed.), Categories of human learning. New York: Academic Press, 1964. Pp. 48-77.

UNDERWOOD, B. J., \& SCHULTZ, R. W. Meaningfulness and verbal learning. Philadelphia: Lippincott, 1960.

\section{NOTE}

1. This research was supported by the Department of Defense, Project THEMIS Contract DAAD05-68-C-1076, under the Department of the Army, to the Institute for the Study of Cognitive Systems, through the TCU Research Foundation.

\title{
Arousal as a function of background factors in psychological experiments'
}

\author{
STEPHEN KAPLAN and KENNETH \\ WINTER, University of Michigan, Ann \\ Arbor, Mich. 48104
}

Two background factors in laboratory research are explored in terms of their effects on the arousal level of Ss. One factor is the laboratory environment as a whole, assessed by comparing arousal levels obtained there to levels obtained during equivalent activities in Ss'homes. Secondly, arousal levels of experienced, paid Ss are compared to those of inexperienced, unpaid Ss. An interaction between these factors unexpectedly partitioned the set of Ss into a low-arousal and a high-arousal group and suggested a reinterpretation of the psychological significance of the factors responsible. Until future research establishes more decisively the relevance of these background factors, auxiliary skin-resistance recording during experiments can help investigators control for these effects.

In designing studies and generalizing from their findings, psychologists necessarily ignore many of the myriad factors which might influence the Ss' behavior in the laboratory experiment. "Irrelevant" characteristics and behaviors of the $E$, the appearance and atmosphere of the laboratory, and the Ss' motivations, intentions, and previous experience, for example, generally are not considered in research reports. Factors which are excluded from explicit research designs might appropriately be called "background factors." In recent years, a number of investigators have sought to bring these background factors into the foreground by explicitly examining their effects. They have undertaken direct studies of what actually happens in the laboratory environment, and have found that background factors of ten increase the probability of Type II errors, and worse, systematically bias the data obtained in this environment (Orne, 1962; Rosenthal, 1966; Friedman, 1967; Argyris, 1968).

Rather than dealing with any specific overt behavior, this study is concerned with the relationship between background factors and a "central" concept, arousal. Arousal, often measured by electrodermal recording (van Olst \& Orlebeke, 1967), has been found to have a pervasive influence on a wide range of processes and behaviors of interest to the psychologist. With respect to background factors the overall arousal level of the $\mathrm{S}$ seems more appropriate than momentary arousal reactions. The Basal Skin Resistance (BSR), which is commonly used for obtaining such a base level, also has the advantage of being relatively simple to record and score as a supplementary measure in any experiment (Kaplan \& Hobart, 1964, 1965). This measure has been used successfully in a variety of different settings. For example, it has been shown to be related to reaction time (Elliott, 1964; Andreassi, 1966), perceptual sensitivity (Martin \& Edelberg, 1963; Fiss, 1966), and learning and memory (Berry, 1962; Kleinsmith, Kaplan, \& Tarte, 1963; Levonian, 1968).

The effects of background factors on behavior vary greatly depending on the kind of behavior measured, so much so that a generally applicable conception of background effects has yet to emerge. Arousal measurement may contribute to a more coherent picture in this area. Arousal is very likely to be influenced by at least some background factors of interest, and has already been shown to be related to a wide variety of processes and behaviors. The particular background factor studied in this experiment was the laboratory environment as a whole. The BSR levels were compared for the same Ss when they were at their campus home and in the laboratory. Virtually identical tasks were being performed in the two settings.

In addition to the "lab-home" dichotomy, differences between two "types" of Ss, "neophytes" and "veterans," were explored. These two types represent the two main ways in which university laboratories obtain their Ss, students fulfilling course requirements and paid volunteers.

\section{SUBJECTS}

Sixteen male honors students served as Ss. Eight of these, the "neophytes," had no previous experience as Ss and served in partial fulfillment of a course requirement. The other eight, the "veterans," were volunteer paid Ss who had previously been in at least two experiments, including at least one in our laboratory.

PROCEDURE

Each $S$ participated in two sessions, separated by 1 or 2 days, and both run at the same time of day. The "lab" session occurred in a $7 \times 7 \mathrm{ft}$ windowless room, somewhat cluttered with equipment from other ongoing experiments. The "home" session took place wherever $S$ said he usually studied at home, generally at a desk. The $S$ either was alone in his room or was asked not to converse with roommates present during the "home" session. For half of each of the two S groups the "lab" session occurred first, while the other half started with the "home" session.

Each session was divided into two portions. The first $10 \mathrm{~min}$ were spent doing timed tasks including paired-associate memorization and recall and a paper-andpencil visual search task. Parallel forms of these tasks were constructed for the two sessions. The following $30 \mathrm{~min}$ were spent doing homework or other reading of S's own choice and at S's own speed. These self-selected activities were restricted only in that each $S$ was asked to read approximately 
the same kind of material in each of the sessions.

In the "lab" session, E was present during the timed tasks, reading instructions aloud and timing the tasks. The $E$ then left the room for the self-selected study period and retumed at the end of the session. In the "home" session, E merely connected the recording equipment and departed immediately. Left to himself, $S$ executed the entire procedure by following printed instructions identical to those given verbally in the "lab" session. The $S$ was given a timer to use in self-administering the timed tasks.

Skin resistance was recorded throughout both sessions using a semiportable, constant current, wideband recording system (Kaplan $\&$ Hobart, 1964) and nonpolarizing fingertip electrodes (Kaplan \& Fisher, 1964). For each session, four BSR scores were computed, each representing the mean resistance level during a 2 -min segment of the session. Segments scored were as follows: (a) the middle $2 \mathrm{~min}$ of the paired-associate task; (b) the middle 2 min of the search task; (c) the second and third minutes of the self-selected activity period; and (d) the last 2 min of the self-selected activity period. For each session the mean of these four scores for each $\mathrm{S}$ was used in the analyses.

\section{RESULTS AND DISCUSSION}

While the distribution of mean BSR scores for the "home" session was roughly normal, the BSR scores for the "lab" session were strongly bimodal. No $S$ had a mean score between 125 and $185 \mathrm{Kohms}$ in the "lab" setting, while the majority of BSR means in the "home" setting fell in this range. This bimodality can be accounted for by the interaction between an "order of sessions" (whether Ss had the "home" or the "lab" condition first) and the "neophyteveteran" factor $[F(1,12)=18.38$, $\mathrm{p}<.005]$. The "veterans" who first worked at "home" and the "neophytes" who first had the "lab" sessions had a mean BSR of $185 \mathrm{Kohms}$. On the other hand, the "veterans" who started with the "lab" session and the "neophytes" who first worked at "home" had a significantly higher arousal level, a mean BSR of $106 \mathrm{Kohms.}$

These data clearly call for a revision of the a priori descriptions of the "lab-home" factor, particularly the nature of the "home" session. The original notion was that the more familiar and tranquil "home" environment would relax Ss, giving lower arousal in the "home" session. If any thing, there was a trend in the opposite direction. It appears that the extra activity and responsibility required of Ss during this session rendered the broader setting irrelevant. At home, Ss were on their own. It was up to them to execute the session, whereas in the laboratory they had but to follow E's instructions. Two Ss spontaneously reported some anxiety during the "home" session lest the recording equipment break down while they were "in charge" of it. Perhaps "home" and "lab" ąre misnomers for the two sessions. They might better be called, respectively, the "active-responsible" and the "passive-compliant" sessions.

The "veterans-neophytes" factor also requires a closer look. The "veterans" had been lured by an advertisement promising easy work and easy money; our experience is that paid Ss manifest relatively little enthusiasm for experimental activities. (In one study in our laboratory, where Ss were left alone to do a boring task, paid Ss occasionally walked out in the middle of a session, while Ss from introductory courses never did). Though the "neophytes" participation was enforced by a course requirement, an emphasis is placed on the educational possibilities in the experience, and arrangements are provided for subsequent discussions of the study. Organizational research gives additional grounds for believing that "veterans" would have an employee-like attitude while "neophytes" would find the experiment more intrinsically involving (Argyris, 1968). In short, it would seem that the "veterans" perceived the experiment as a job and the "neophytes" perceived it as a challenge.

Finally, the stability of the BSR scores across sessions requires some explanation. There are indications in the data that $S$ 's reaction to his first encounter with this experiment, as reflected in first-session BSR, had a "pace-setter" effect, determining the general arousal level he maintained throughout both sessions. The Ss in this study were told in advance that the two sessions would be "identical," and their "lab" and "home" BSRs had a rank-order correlation of .69 $(p<.001)$. In other multiple-session studies where sessions were not announced as identical, this correlation has been much lower. The general "pace-setter" hypothesis would be that to the extent that a person's first encounter with a situation establishes a perception of or attitude toward the situation which carries over to subsequent encounters, his arousal levels will tend to be similar.

Thus, for the "veterans," with their employee-like attitude, the fact that the "boss" (E) was present watching their performance in the laboratory made that the more stressful session. For the "veterans," a first session in the lab was therefore a high-arousal "pace-setter," while a first session in the unsupervised "home" setting established a low-arousal reaction to the experiment. For the "neophytes," for whom the challenge of the activities was the main determinant, the active-responsible nature of the "home" session established a high-arousal pattern in those who went "home" first, while the passive-compliant "lab" session set a low-arousal pace for the "neophytes" who had this session first. The net result of these factors, then, is the interaction effect between the veteranneophy te factor and the order of sessions.

It thus appears that the source of Ss and the perceived nature of the experimental task are important as determinants of arousal level in experiments and, moreover, interact to produce unexpected patterns. More research along these lines appears sorely needed. For the present, an investigator might be wise to use a simple auxiliary electrodermal recording system to detect such effects.

\section{REFERENCES}

ANDREASSI, J. L. Skin-conductance and reaction-time in a continuous auditory monitoring task. American Journal of Psychology, $1966,79,470-474$.

ARGYRIS, C. Some unintended consequences of rigorous research. Psychological Bulletin, 1968, 70, 185-197.

BERRY, R. N. Skin conductance levels and verbal recall. Journal of Experimental Psychology, 1962,275-277.

ELLIOTT, R. Physiological activity and performance: A comparison of kindergarten children with young adults. Psychological Monographs, $1964,78(10$, Whole No. 587).

FISS, H. The effects of experimentally induced changes in alertness on response to subliminal stimulation. Journal of Personality, 1966, 34, 577-595.

FRIEDMAN, N. The social nature of psychological research. New York: Basic Books, 1967.

KAPLAN, S., \& FISHER, G. R. A modified design for the Lykken zinc electrodes. Psychophysiology, 1964, 1, 88-89.

KAPLAN, S., \& HOBART, J. L. A versatile device for the measurement of skin resistance in rats and humans. American Journal of Psychology, 1964, 77, 309-310.

KAPLAN, S., \& HOBART, J. L. New technique for recording skin resistance. American Journal of Medical Electronics, 1965, 4, 117-120.

KLEINSMITH, L. J., KAPLAN, S., \& TARTE, R. D. The relationship of arousal to short- and long-term verbal recall. Canadian Joumal of Psychology, 1963, 17, 393-397.

LEVONIAN, E. Short-term retention in relation to arousal. Psychophysiology, 1968, 4, 284-293. MARTIN, R. D., \& EDELBERG, R. The relationship of skin resistance changes to receptivity. Journal of Psychosomatic Research, 1963, 17, 173-179.

ORNE, M. T. On the social psychology of the psychological experiment. American Psychologist, 1962, 17,776-783.

ROSENTHAL, R. Experimenter effects in behavioral research. New York: AppletonCentury-Crofts, 1966.

van OLST, E. H., \& ORLEBEKE, J.F. An analysis of the concept of arousal. Psychologie, 1967, $12,583-603$.

\section{NOTE}

1. This investigation was supported in part by Research Grant MH-11599 from the National Institute of Mental Health, United States Public Health Service, to Stephen Kaplan and Rachel Kaplan. The authors are indebted to the latter for her help throughout this project. The study was conducted while the second author was an NSF Predoctoral Fellow. 